\title{
Health-related Quality of Life Determinants in Outpatients With Heart Failure ${ }^{1}$
}

\author{
Viviane Martinelli Pelegrino² \\ Rosana Aparecida Spadoti Dantas ${ }^{3}$ \\ Alexander Michael Clark ${ }^{4}$
}

This descriptive and exploratory study analyzed variables associated with health-related quality of life among 130 outpatients. Health-related quality of life was measured through the Minnesota Living with Heart Failure Questionnaire. Significant associations were found between patients' health-related quality of life and their age $(r=-0.177 ; p=0.044)$, vitality $(r=-0.625 ; p=<0.001)$ as well as mental health $(r=-0.672 ; p=<0.001)$, which are both SF36 domains. The linear regression showed that heart failure symptom severity, vitality and mental health explained $54 \%$ of HRQOL measurement variation. To control symptoms and preserve good mental well-being are important to maintain health-related quality of life and to deliver effective heart failure care.

Descriptors: Heart Failure; Quality of Life; Mental Health; Symptoms.

\footnotetext{
${ }_{1}^{1}$ Paper extracted from Master's Dissertation "Avaliação do estado de saúde percebido e do impacto da insuficiência cardíaca por pacientes em seguimento ambulatorial", presented to Escola de Enfermagem de Ribeirão Preto, Universidade de São Paulo, WHO Collaborating Centre for Nursing Research Development, SP, Brazil.

2 RN, Hospital das Clínicas, Faculdade de Medicina de Ribeirão Preto, Universidade de São Paulo, Brasil. Master's Student, Escola de Enfermagem de Ribeirão Preto, Universidade de São Paulo, WHO Collaborating Centre for Nursing Research Development, SP, Brazil. E-mail: vivi.pelegrino@bol.com.br.

${ }^{3}$ RN, Ph.D. in Nursing, Associate Professor, Escola de Enfermagem de Ribeirão Preto, Universidade de São Paulo, WHO Collaborating Centre for Nursing Research Development, SP, Brazil. E-mail: rsdantas@eerp.usp.br.

${ }^{4}$ Associate Professor, Faculty of Nursing, University of Alberta, Edmonton, Canada. E-mail: alex.clark@ualberta.ca.
}

Corresponding Author:

Viviane Martinelli Pelegrino

Universidade de Sao Paulo. Escola de Enfermagem de Ribeirao Preto

Departamento de Enfermagem Geral e Especializada. Sala 69

Av. dos Bandeirantes, 3900

Bairro: Monte Alegre

CEP: 14040-902 Ribeirao Preto, SP, Brasil

E-mail: vivi.pelegrino@bol.com.br 


\title{
Determinantes da qualidade de vida relacionada à saúde em pacientes ambulatoriais com insuficiência cardíaca
}

Trata-se de estudo descritivo e exploratório que analisou as variáveis associadas à qualidade de vida relacionada à saúde (QVRS), de 130 pacientes com insuficiência cardíaca, em seguimento ambulatorial. A QVRS foi avaliada pelo Minnesota Living with Heart Failure e realizada análise de regressão linear. A média da QVRS foi de 34,9 $(d p=24,8$; intervalo de 0 a 99). Foram encontradas associações significantes entre a medida da QVRS e idade $(r=-0,177 ; p=0,044)$, vitalidade $(r=-0,625 ; p=<0,001)$ e saúde mental $(r=-0,672 ; p=<0,001)$, domínios do SF-36. A regressão linear mostrou que a gravidade dos sintomas da insuficiência cardíaca, e dois domínios do SF-36, vitalidade e saúde mental, explicaram 54\% da variação da medida da QVRS. Controlar os sintomas e manter bem-estar mental é essencial para a manutenção da QVRS e são essenciais para o cuidado eficaz da insuficiência cardíaca.

Descritores: Insuficiência Cardíaca; Qualidade de Vida; Saúde Mental; Sintomas.

\section{Determinantes de la calidad de vida relacionada a la salud en pacientes atendidos en ambulatorios con insuficiencia cardíaca}

\begin{abstract}
Se trata de un estudio descriptivo y exploratorio que analizó las variables asociadas a la calidad de vida relacionada a la salud (CVRS) de 130 pacientes con insuficiencia cardíaca en seguimiento en ambulatorio. La CVRS fue evaluada por el Minnesota Living with Heart Failure y realizado análisis de regresión linear. El promedio de la CVRS fue de 34,9 $(D E=24,8$; intervalo de 0 a 99). Fueron encontradas asociaciones significantes entre la medida de la CVRS y edad $(r=-0,177 ; p=0,044)$, vitalidad $(r=-0,625 ; p=<0,001)$ y salud mental $(r=-0,672 ; p=<0,001)$, dominios del SF-36. La regresión linear mostró que la gravedad de los síntomas de la Insuficiencia Cardíaca, y dos dominios del SF36 , vitalidad y salud mental, explicaron $54 \%$ de la variación de la medida de la CVRS. Controlar los síntomas y mantener el bienestar mental es esencial en la manutención de la CVRS y son esenciales para el cuidado eficaz de la Insuficiencia Cardíaca.
\end{abstract}

Descriptores: Insuficiencia Cardíaca; Calidad de Vida; Salud Mental; Síntomas.

\section{Introduction}

Heart Failure (HF) has been an increasing public health problem in developed countries. Its increase is usually associated with population age, the wide prevalence of cardiovascular risk factors and other diseases. HF is associated with complications like obesity and diabetes, and improved survival rates from myocardial infarction ${ }^{(1)}$.

$\mathrm{HF}$ is also a growing concern in developing countries. In Brazil, HF affects over two million people, with 240,000 new diagnoses per year ${ }^{(2)}$. HF is present in one third of patients who are treated by the public health system in Brazil, which mostly attends the country's oldest and poorest people. HF is the main cause of heart-related hospitalizations in the public health system $(293,759$ admissions in 2007), with an annual mortality rate of about $8 \%$ and approximately 23,442 deaths each year(2).

Heart failure patients face a wide variety of symptoms that can adversely impact their quality of life. Physical and psychological symptoms are widely reported. Patients with heart failure face significant decreases in functional status, multiple hospital admissions, high mortality, multiple physical and psychological symptoms and a diminished quality of life ${ }^{(3)}$.

It is well known that HF significantly worsens healthrelated quality of life (HRQOL) by reducing patients' 
functional capacity and ability to perform activities of daily living. HRQOL encompasses various aspects of selfperceived well-being, which are related to or affected by the presence of a disease and/or treatment(3).

The effects on HRQOL size are influenced by many factors, including patient age, gender, left ventricular dysfunction, New York Heart Association (NYHA) functional class, HF severity, mortality risk and mental health ${ }^{(3-4)}$. Heart failure patients face a wide variety of physical (dyspnea, fatigue, pain, edema, loss of appetite) and psychological (anxiety and depression) symptoms that can adversely impact their quality of life ${ }^{(3)}$. Female patients tend to report more physical limitations and depressive symptoms compared with male patients ${ }^{(5)}$.

In combination, these factors place severe limitations on their daily living activities and have adverse effects on physical and mental health and perceived quality of life. For example, fatigue reduces autonomy and independence for daily activities ${ }^{(6)}$. However, though quality of life is measureable, it is also a complex and multi-faceted construct that is prone to cultural and social differences. To date, HRQOL during $\mathrm{HF}$ has been studied mostly in the United States ${ }^{(7-10)}$, Canada(11) Europe ${ }^{(12-14)}$ and Asia(15). Due to a lack of studies, little is known about how HF influences HRQOL in South American populations(16-17).

This study was guided by the question: "What are the associations among health-related quality of life, demographic and clinical variables in heart failure outpatients followed at a public hospital in Brazil?"

To address this knowledge gap, this study sought to identify the predictors of Health-related quality of life in heart failure patients followed at a public hospital in Brazil.

\section{Method}

\section{Design, setting and subjects}

A larger study that used an observational crosssectional design was based at the University Hospital, Hospital das Clínicas in Ribeirão Preto, São Paulo state, which attends a mixed rural and urban population all over the Southeastern region of Brazil. Approval for the study was obtained from the Institutional Review Board at the School of Medicine. Participants were recruited from the Cardiology Division of the University Hospital. Eligible participants were recruited from a single specialty HF clinic in the hospital. Inclusion criteria included people aged 18 years or older, HF diagnosis based on clinical signs, radiological, and echocardiography findings, and a medical visit at the Cardiomyopathy Specialized Clinic of the University Hospital during the study period. Exclusion criteria included the presence of neurological disorder, major psychiatric condition (such as dementia or schizophrenia), or cognitive impairment.

The enrollment period ranged from February 2005 to August 2006, 138 patients were invited to participate in the study. Two patients declined to participate and 6 patients could not participate due to their physical, psychological or cognitive conditions. Overall, a convenience sample of 130 patients was analyzed in the study.

\section{Data collection and instruments}

Data were collected immediately after the individual's medical visit. Other clinical data were obtained through a review of patients' medical records. To test comprehension and relevance of data collection instruments, a pilot test was performed on ten subjects. As no changes were necessary, those patients were included in the final sample.

The instruments used to measure the variables were the following:

- Health-related quality of life: it was measured using the total score of the Minnesota Living with Heart Failure Questionnaire (MLHFQ) ${ }^{(8)}$. The MLHFQ total scale ranged from zero to 105 , with lower scores meaning better HRQOL. This measurement tool is reliable and valid(3). The Portuguese version of the MLHFQ(17) was used and the internal consistency for the total scale was 0.93 in the present study.

- Perceived mental health status: it was measured using the two domains from the Medical Outcomes Study SF36: mental health (psychological distress and well-being) and vitality (energy and fatigue) ${ }^{(18)}$. In a possible range from zero to 100 , higher scores reflect better health perception in both domains. The SF-36(19) Portuguese translation was culturally adapted to Brazil and it was found reliable and valid in HF patients ${ }^{(16)}$. Hence, it was also used.

- Other Variables: Demographic data collected during the interview included age, gender, educational level (in years), marital status (married/have a partner versus not), and work status (having a paid job versus not). Clinical data were: HF etiology, length of followup for HF disease (in years). Left Ventricular Ejection Fraction (LVEF) echocardiography test was analyzed to measure left ventricular dysfunction, New York Heart Association Functional Class (NYHA-FC I, II, III e IV) 
to measure HF symptoms, number of co-morbidities, number of medications prescribed, and artificial pacemaker presence or resynchronization therapy. Clinical variables were also grouped: LVEF (less than $30 \%$ and between $30 \%$ and $44 \%$ ); and the NYHAFunctional Class (class I for asymptomatic HF and classes II to IV for symptomatic HF).

\section{Data analysis}

The data were analyzed using the statistical software SPSS (Statistical Package for Social Science version 15.0). Descriptive analysis was performed for all variables. To assess the association of demographic and clinical variables to HRQOL, univariate analyses based on Pearson's correlation was calculated for numerical variables. For categorical explanatory variables, Student's t test was performed to assess differences in mean MLHFQ total score among the categories. Pearson's correlations were calculated between the continuous variables (age, educational background, follow-up HF disease length of time, and Left Ventricular Ejection Fraction) and HRQOL (measured by MLHFQ total score). Linear regression analysis using a stepwise regression model was performed for multivariate investigation of the association between the HRQOL measure and demographic, clinical, and perceived mental health variables. Age and gender were considered factors that were a prior presence in HF and were controlled before clinical variables. The significance level was 0.05 .

\section{Results}

One hundred and thirty patients were included. Their average age was 55.1 (s.d. $=14.9$ ) and most of them were less than 60 years old $(78 ; 60 \%)$. The majority was male $(n=77,59.2 \%)$, married or living with a partner $(80,61.5 \%)$, they had a low education level (four years of formal study on average), and no paid employment $(107,82.3 \%)$ (Table 1$)$.

The patients' length of inclusion into the specialty $\mathrm{HF}$ clinic was 1.5 years on average, ranging from zero (i.e. patients who were beginning the follow-up on the day of the interview) to 4.8 years. Most of the patients (80; 61.6\%) were symptomatic in NYHA-Functional Class II-IV. The mean LVEF was $27 \%$ (s.d. = 29; range from $10 \%$ to $43 \%) ; 46.9 \%$ had severe LVEF and $32.3 \%$ had moderate LVEF dysfunction. Twenty-one patients $(15.4 \%)$ had an artificial pacemaker due to bradycardia and none of them had resynchronization therapy (Table 1 ).

Fifty-nine participants $(44.3 \%)$ reported at least one comorbidity, and 86 (47\%) participants showed associated diseases, such as: systemic arterial hypertension, chronic atrial fibrillation, arrhythmias, and hyperthyroidism. Among the participants, there was a large variation regarding medication uses, with subjects using from one to ten different classes of medication ( mean $=5.8$ e s.d. $=1.8$ ). The most common medications used by the patients and reported in the medical records were diuretics, Angiotensin-converting enzyme, Betablockers and digitalis.

Table 1 - Characteristics of sample $(n=130)$

\begin{tabular}{lc}
\multicolumn{1}{c}{ Characteristics } & Mean (s.d.) or $\mathbf{n ~ ( \% ) ~}$ \\
\hline Age & $55.1(14.9 \%)$ \\
Less than 60 & $78(60.0 \%)$ \\
60 or more & $52(40.0 \%)$ \\
Male & $77(59.2 \%)$ \\
Marital Status (married/partnered) & $80(61.5 \%)$ \\
Educational background (years) & $3(3.9 \%)$ \\
Work status (having no paid job) & $107(82.3 \%)$ \\
length of HF follow-up (in years) & $1.5(1.4 \%)$ \\
Functional Class (NYHA) & \\
I (asymptomatic) & $49(37.7 \%)$ \\
II/III or IV (symptomatic) & $80(61,6 \%)$ \\
not informed & $1(0.7 \%)$ \\
Left Ventricular Ejection Fraction & $27 \%(29 \%)$ \\
less than 30\% (severe dysfunction) & $61(46.9 \%)$ \\
from 30 to 40\% (moderate) & $42(32.3 \%)$ \\
not informed & $27(20.8 \%)$ \\
Pacemaker presence (yes) & $21(15.4 \%)$ \\
\hline
\end{tabular}

Regarding HRQOL, the mean MLHFQ was: 34.9 (s.d. = 24.8; range from 0 to 99). The association between HRQOL and age was negative and weak ( $r=-$ $0.177 ; p=0.044$ ), although statistically significant. Weak associations were found between HRQOL and length of HF follow-up ( $r=-0.233 ; p=0.015)$, as well as HRQOL and left ventricular ejection fraction $(r=-0.236 ; p=0.017)$ (Table 2). No association was found between HRQOL and educational background $(r=0.004 ; p=0.960)$. However, Perceived Mental Health, the exploratory variable of interest, measured by the vitality $(r=-.625, p<0.001)$ and mental health domains $(r=-0.672, p<0.001)$ of the SF-36, showed strong significant associations with HRQOL (Table 2). 
Table 2 - Zero order correlation between HRQOL (MLHFQ total score) and explanatory variables

\begin{tabular}{lcc}
\hline \multicolumn{1}{c}{ Explanatory variables } & $\boldsymbol{r}^{*}$ & $\boldsymbol{p}_{\text {-value }}{ }^{\dagger}$ \\
\hline Age (years) & -0.177 & .044 \\
Educational background (years) & 0.004 & .960 \\
Length of HF follow-up (years) & -.0213 & .015 \\
Left Ventricular Ejection Fraction & -0.236 & .017 \\
Vitality (SF-36 domain) & -0.625 & $<.001$ \\
Mental Health (SF-36 domain) & -0.672 & $<.001$ \\
\hline
\end{tabular}

* Pearson's correlation; $+p$-value

No association was found between HRQOL and demographic variables. Although younger and female patients had higher MLHFQ Total scores (indicating perception of more negative $\mathrm{HF}$ effects on quality of life) than older and male patients, differences were not significant ( $p=0.092$ and $p=0.052$, respectively). Nor did HRQOL vary based on marital status (Table 3). Health-related quality of life was significantly lower in patients with worse symptoms (NYHA Class II, III and IV; $p<0.001$ ) but non-significant differences were associated with severe left ventricular dysfunction (less than 30\%; $p=0.054$ ) (Table 3).

The multivariate analysis was performed using a two-stepwise regression model, constructed first by entering NYHA Classification and then Mental Health and Vitality into the model. After entering the first step, the adjusted $r^{2}$ was 0.204 . Hence, the presence of HF symptoms explained, by itself, about $20 \%$ of variance in the HRQOL measure. When adding Mental Health and Vitality scales, R2 increased to 0.496 (49\% of the HRQOL variance) and this increase was statistically significant ( $p$-values $<0.001)$. The final model explained $54 \%$ of total MLHF scale variation and, also, vitality and mental health together with NYHA Functional Class explained $34 \%$ of variance (Table 4 ).

Table 3 - Mean of MLHFQ total scale by Categorical Explanatory Variables

\begin{tabular}{llc}
\hline \multicolumn{1}{c}{ Explanatory variables } & Mean (s.d.) & p-value* \\
\hline Gender & $39.3(23.3)$ & 0.092 \\
Female & $31.8(25.4)$ & \\
Male & & \\
Age (years) & $38.3(25.6)$ & 0.052 \\
Less than 60 & $29.7(22.7)$ & \\
60 or more & & \\
Marital status & $35.4(25.7)$ & 0.869 \\
$\quad$ Married/living with significant other & $34.6(23.5)$ & \\
Widowed/Divorced/Separated/Single & & \\
Functional Class (NYHA) & $21.0(16.7)$ & $<0.001$ \\
I (asymptomatic) & $42.7(23.9)$ & \\
II/III or IV (symptomatic) & & \\
Left Ventricular Ejection Fraction & $39.6(26.6)$ & 0.054 \\
$\quad$ Less than 30\% (severe dysfunction) & $29.8(22.2)$ & \\
From 30 to 40\% (moderate) & & \\
\hline
\end{tabular}

* $p$-value from Student's t test

Table 4 - Regression Analysis MLHFQ total score as the Outcome

\begin{tabular}{|c|c|c|c|c|c|}
\hline Explanatory Variable & Coefficient & St. Error & $p$-value* & $\mathbf{r} 2^{\dagger}$ & $p$-value ${ }^{\ddagger}$ \\
\hline \multicolumn{6}{|l|}{ STEP 1} \\
\hline \multicolumn{6}{|l|}{ NYHA Functional Class (ref.: Class I) } \\
\hline Classes II, III, IV & 0.460 & 4.537 & 0.00 & 0.204 & 0.00 \\
\hline \multicolumn{6}{|l|}{ STEP 2: } \\
\hline NYHA Functional Class & 0.300 & 3.764 & 0.00 & & \\
\hline Mental Health & -0.566 & .78 & 0.00 & 0.496 & 0.00 \\
\hline \multicolumn{6}{|l|}{ STEP 3: } \\
\hline NYHA Functional Class & 0.208 & 3.725 & 0.00 & & \\
\hline Mental Health & -0.477 & .096 & 0.00 & & \\
\hline Vitality & -0.195 & .104 & 0.33 & 0.541 & 0.00 \\
\hline
\end{tabular}

* $p$-value from Student's t test; + Pearson's correlation; $\neq p$-value

\section{Discussion}

The contribution of perceived mental health (measured by Vitality and Mental Health SF-36 subscales) to explain the variance in HRQOL was high (31\%) after adjusting for demographic and clinical variables. This is consistent with results usually obtained from observational studies in clinical research(14). These results support the hypothesis that symptom severity and psychological factors (such as mood, depression and anxiety) significantly contribute to HRQOL in $\mathrm{HF}$ patients $^{(9-10,20)}$. The levels of HRQOL in our study were similar to those found in other patients with $\mathrm{HF}$ in $\operatorname{Brazil}^{(16,19,21)}$ and in the USA ${ }^{(5,10,14)}$.

The participants in this study were predominantly less than 60 years old, male, married, with low educational level and without paid employment. Most of the patients were symptomatic, and they were classified 
as having severe LVEF or moderate LVEF dysfunction. Among the participants, lower HRQOL was associated with severity of HF symptoms (NYHA functional Classes II, III e IV), and severe left ventricular dysfunction. These findings are consistent with studies undertaken in the United Kingdom ${ }^{(14)}$ and the United States ${ }^{(4,7-8)}$. In line with other studies, younger patients and women had lower HRQOL ${ }^{(3-4)}$, but there was no association with marital status. Physical symptom status was the most powerful predictor of HRQOL in patients with heart failure(22).

The patients in this study primarily had a lower socio-economic status and showed high levels of low literacy, but this is typical for patients treated in Brazilian public hospitals ${ }^{(16,19,21-23)}$. The HF sample was also similar to populations from other studies in Brazil(16,21,24). Although samples used in other studies from the USA ${ }^{(8,25)}$ and Spain ${ }^{(20)}$ showed similar characteristics, most of the samples have considerably higher socio-economic and educational levels. In the future, we propose including this kind of population in a new study in order to improve our knowledge about that population's health.

The impact of HF symptoms is both physical and psychosocial and how to manage these symptoms effectively is a cornerstone of HF management success and self-care ${ }^{(3,10)}$. Given the importance of HRQOL to patients, the adaptation of disease management interventions to support effective self-care of HF in Brazil is a priority ${ }^{(16-17,24)}$. Programs to support self-care should include both patients and partners and examine ways to ensure that the many facets of these interventions are accessible and beneficial to patients with very low socioeconomic and educational levels ${ }^{(9,24-25)}$.

These results suggest that the development and provision of interventions to improve psychological status may improve physical symptom status and HRQOL in HF patients ${ }^{(22)}$. Those most at risk for diminished quality of life are those of younger age, worse functional status, increased symptom prevalence and increased symptom burden ${ }^{(3)}$. Though provision of these therapies to the larger population with depressive symptoms will be costly, this may be offset via reduced re-hospitalization rates, which are also common in HF patients from Brazil.

\section{Conclusion}

Regarding the effects of $\mathrm{HF}$ on HRQoL, there was a weak association between HRQoL and the length of HF follow-up, as well as between HRQoL and the left ventricular ejection fraction. However, Perceived Mental
Health, the exploratory variable of interest, measured by the vitality and mental health domains of the SF-36, was significantly associated with HRQoL. The contribution of perceived mental health to explain the variance in HRQoL was higher after adjusting for demographic and clinical variables. These results support the hypothesis that symptom severity and psychological factors significantly contribute to improve HRQOL in HF patients. Our findings indicated the importance of keeping control of HF symptoms and mental health improvement.

The study is limited by its cross-sectional design and limitations regarding the number of variables that could be measured. Further, longitudinal studies are needed to examine the influence of clinical and psychosocial dimensions on HRQoL across the HF trajectory. Our results suggest that interventions tailored to improve self-perceived vitality and mental health may be worth it to maintain a high level of HRQoL in chronic HF conditions.

\section{References}

1. Rosamond W, Flegal K, Furie K, Go A, Greenlund $\mathrm{K}$, Haase $\mathrm{N}$, et al. Heart disease and stroke statistics2008 update: a report from the American Heart Association Statistics Committee and Stroke Statistics Subcommittee. Circulation. 2008;117(4):e25-146.

2. Datasus - Departamento de Informática do SUS. [homepage na Internet] Brasília: Ministério da saúde c2008-2009 [acesso 1 dez 2009]. Disponível em: http:// tabnet.datasus.gov.br/cgi/idb2008/matriz.htm.

3. Zambroski CH, Moser DK, Bhat G, Ziegler C. Impact of symptom prevalence and symptom burden on quality of life in patients with heart failure. Eur J Cardiovasc Nurs. 2005; 4(3):198-206.

4. Clark DO, Tu W, Weiner M, Murray MD. Correlates of health-related quality of life among lower-income, urban adults with congestive heart failure. Heart Lung. 2003;32(6):391-401.

5. Littik ML, Lesman-Leegte I, Jaarsma T. Quality of life and depressive symptoms in heart failure patients and their partners: the impact of role and gender. J Card Fail. 2009;15(7):580-5.

6. Fini A, Cruz DALM. Characteristics of fatigue in heart failure patients: a literature review. Rev. Latino-Am. Enfermagem. 2009;17(4):557-65.

7. Carels RA. The association between disease severity, functional status, depression and daily quality of life in congestive heart failure patients. Qual Life Res. 2004; 13:63-72. 
8. Rector TS, Kubo SH. Patients' self-assessment of their congestive heart failure. Heart Fail. 1987;(3):198-209. 9. Heo S, Lennie TA, Okoli C, Moser DK. Quality of life in patients with heart failure: ask the patients. Heart Lung. 2009;38(2):100-8.10.

10. Artinian NT, Harden JK, Kronenberg MW, Vander JS, Daher E, Stephens Q, et al. Pilot study of a Web-based compliance monitoring device for patients with congestive heart failure. Heart Lung. 2003;32(4):226-33.

11. Ducharme A, Doyon O, White M, Rouleau JL, Brophy JM. Impact of care at a multidisciplinary congestive heart failure clinic: a randomized trial. CMAJ. $2005 ; 173(1): 40-5$.

12. Ekmam I, Fagerberg B, Lundman B. Health-related quality of life and sense of coherence among elderly patients with severe chronic failure in comparison with healthy controls. Heart Lung. 2002;31(2):94-101.

13. Middel B, Bouma J, Jongste $M$, van Sonderem $E$, Niemeijer MG, van den Heuvel W. Psychometric properties of the Minnesota Living with Heart Failure Questionnaire (MLHF-Q). Clin Rehabil. 2001;15(5):489-500.

14. Hobbs FD, Kenkre JE, Roalfe AK, Davis RC, Hare R, Davies MK. Impact of heart failure and left ventricular systolic dysfunction on quality of life: a cross-sectional study comparing common chronic cardiac and medical disorders and a representative adult population. Eur Heart J. 2002;23(23):1867-76.

15. Jeng $\mathrm{C}$, Yang $\mathrm{MH}$, Chen $\mathrm{PL}, \mathrm{Ho} \mathrm{CH}$. The influence of exercise tolerance on quality of life among patients with heart failure. Qual Life Res. 2004;13:925-32.

16. Scattolin FAA, Diogo MJD, Colombo RCR. Correlation between instruments for measuring health-related quality of life and functional independence on elderly with heart failure. Public Health. 2007;23(11):2705-15. 17. Carrara D. Avaliação prospectiva da qualidade de vida em pacientes com miocardiopatia dilatada submetidos à ventriculectomia parcial esquerda. [dissertação de mestrado]. São Paulo (SP): Faculdade de Medicina da Universidade de São Paulo; 2001. 77 p.

18. Ware JE, Sherbourne CD. The MOS 36-item shortform health survey (SF-36). I. Conceptual framework and item selection. Med Care. 1992;30(6):473-83.

19. Ciconelli RM, Ferraz MF, Santos W, Meinão I, Quaresma MR. Brazilian-Portuguese version of the SF36. A reliable and valid quality of life outcome measure. Rev Bras Reumatol. 1999;39(3):143-50.
20. Rodríguez-Artalejo F, Guallar-Castillon P, Pascual CR, Otero CM, Montes AO, Garcia AN, et al. Health-related quality of life as a predictor of hospital readmission and death among patients with heart failure. Arch Intern Med. 2005;165(11):1274-9.

21. Saccomann IC, Cintra FA, Gallani MCBJ. Psychometric properties of the Minnesota Living with Heart FailureBrazilian version--in the elderly. Qual Life Res. 2007;16(6):997-1005.

22. Heo S, Doering LV, Widener J, Debra K. Moser DK. Predictors and effect of physical symptom status on health-related quality of life in patients with heart failure. Am J Crit Care. 2008;17(2):124-32.21.

23. Dantas RAS, Ciol MA. Quality of life after coronary artery bypass surgery. West J Nurs Res 2008;30(4):477-90.

24. Rabelo ER, Aliti GB, Domingues FB, Ruschel KB, Brun $A O$. What to teach to patients with heart failure and why the role of nurses in heart failure clinics. Rev Latino-Am. Enfermagem. 2007;15(1):165-70.

25. Clark AM, Thompson DR. The future of heart failure disease management programs. Lancet. 2008;372(9641):784-6.
Received: May $5^{\text {th }} 2010$ Accepted: Mar. $15^{\text {th }} 2011$ 